\title{
The Effect of Perception of Early Parental Attachment Experiences on Adult Romantic Attachment Style
}

\author{
Eyob Ayenew \\ Department of Psychology, Arba Minch University, Arba Minch, Ethiopia
}

Email address:

eyobie2002@yahoo.com,manayesh997@gmail.com

\section{To cite this article:}

Eyob Ayenew. The Effect of Perception of Early Parental Attachment Experiences on Adult Romantic Attachment Style. American Journal of Applied Psychology. Vol. 10, No. 3, 2021, pp. 65-69. doi: 10.11648/j.ajap.20211003.12

Received: January 14, 2021; Accepted: March 10, 2021; Published: June 10, 2021

\begin{abstract}
The capacity to form strong intimate relationship with others is considered as an essential developmental task and a principal feature of effective personality development. Consequently, there are different theories that attempted to explain how social relationship is formed. However, review of related literature on such relationship shows that attachment theory has become prominent theory to explain it. The purpose of this study is to examine the influence of early parental (care giver) attachment experience on adult romantic attachment using attachment theory as a framework. Cross-sectional descriptive survey design was used. A total of 306 (159 female and 147 male) participants were included from community based sample. Three Kebeles in Yeka sub-city of Addis Ababa were selected randomly. Data were collected on adult attachment and perception of early parental attachment experience. The constructs were measured by Experience in Close Relationship ScaleRevised and Inventory of Parent Peer Attachment. Pearson correlation and linear multiple regressions were run to investigate the association and prediction among variables under study respectively. The result confirmed that perception of early attachment experience did not predict adult romantic attachment but insignificantly related. Consequently, the relationship between perception of early parental attachment experience and adult romantic attachment style should be studied by fellow researchers to make the study more replicable in the future.
\end{abstract}

Keywords: Perception, Early Attachment, Adult Romantic Attachment Style, Emotional Bond

\section{Background of the Study}

Close relationships is essential to health and well-being. The capacity to form intimate relationship with others is considered as an essential developmental task and a principal feature of effective personality development $[2,4,13]$. Adult intimate relationships are highly complex phenomena and span manifold level of analysis including; the person, his/her social, cultural and historical context of their interactions and the systemic interplay among those levels of analysis [12, 16]. Consequently, there are different theories that attempted to explain intimate relationship. However, review of related literature on intimate relationships shows that attachment theory is becoming prominent theory to explain such relationship $[5,13]$.

Bowlby in his attachment theory [2] suggests that attachment is the deep emotional bond formed between infants and one or more adults; usually a parent or caregiver. This attachment provides a sense of security to children and allows them to explore their environment, returning to the adult during periods of distress. Development of this emotional bond or attachment involves parents providing love, nurturing, trust, safety and respect to their children and sensitively responding to their children's needs. The quality of the early parent-child relationship creates a framework of internalized expectations and beliefs about the self and the self in relation to others. The blueprint of such framework is long lasting and extended to adult romantic relationship [9, 11, 15]. Therefore, attachment system affects the cognitive, emotional and behavioral responses in romantic relationship and expressed in an individual's internal working model of self and others [6]. The model of self and model of others can exist in conscious and unconscious level, which is relatively stable and influences later social and environmental interactions as well as personal developmental experiences.

There is a substantial amount of theoretical evidence suggesting a relationship between early attachment experience and subsequent social functioning. Prominent 
figures of the attachment theory $[1,2,10]$ reported the effect of early attachment experience on adult romantic attachment. However, few studies have been conducted to support the theoretical framework in practice. Some works that had been do so far are supportive while others could not. Therefore, this study investigated the interrelationship between perceptions of early attachment experience with the adult romantic attachment.

\section{Research Methods and Material}

\subsection{Study Area}

The study area is Addis Ababa and was selected purposively. Addis Ababa represents a heterogeneous population in many social characteristics. Addis Ababa is the capital city of Ethiopia established in 1886. It is geographically located at the heart of the country. It accommodates about $35 \%$ of the total urban population in Ethiopia. Addis Ababa City has a total population of 2,738,248 with a growth rate of 2.1 percent per annum (additional 57,503 people per year), where around 52\% of the populations composed of children and adolescents below age 25 years old. From the total population, 48 percent are males and 52 percent are females [7]. This study included heterosexual couples.

\subsection{Research Design and Population}

A non-experimental descriptive survey design was used to investigate the question of interest. The design is nonexperimental because there is no manipulation of independent variables, which were investigated in the study. In this design, the levels or categories of the independent variables were already defined or classified so that the researcher has no opportunity to manipulate or randomly assign individuals to certain groups. Moreover, crosssectional method was used to collect data at a time to make comparisons across different categories of respondents. The target population of this study was adult heterosexual couples while the study population was adult heterosexual couples in Addis Ababa Administrative City. The study site overview and sampling techniques are presented hereafter.

\subsection{Sample Size Determination and Sampling Procedure}

Single proportion population was used to derive the sample size. The proportion of the population in the attributes was not known and $50 \%$ of it was taken. Then at $95 \%$ confidence interval and 0.05 significance level, the sample was size calculated and became 384. Thus, 384 married (cohabited) from a total of 384 households were included in the study.

$$
\mathrm{n}=\left\{\mathrm{Z}^{2} \mathrm{x} \frac{p x q}{\mathrm{~d} 2}\right\}
$$

Where: $\mathrm{n}=$ sample size

$\mathrm{z}=$ Confidence interval (95\%)

$\mathrm{p}=$ Expected prevalence (as fraction of 1$)$

$\mathrm{q}=1-\mathrm{p}$ (expected non-prevalence)

$\mathrm{d}=$ relative desired precision
Yeka sub city was taken purposely among the 10 Woredas in Addis Ababa city. In the sub city, a Woreda with three Kebeles were selected using simple random sampling method. To reach households which are the analysis unit of the study, systematic simple random sampling was used based on the sampling frame obtained from Keble household registration database.

\subsection{Data Collection Tools and Process}

The researcher used a demographic questionnaire and two structured questionnaires. The demographic questionnaire contains nine items that elicits personal information from each respondent. The structured questionnaire includes: Perception of Attachment experience with Parents (IPPA) and Experiences in Close Relationships-Revised (ECR-R).

IPPA measures the degree of closeness between the child and mother and father [2]. Three broad dimensions are assessed: degree of mutual trust; quality of communication; and extent of anger and alienation. Participants were asked to think about their relationships with their mothers and fathers or parental figures before they reached 18 years old. An overall score of positive relationship with each parent (high trust, high communication, and low alienation) was calculated to determine the closeness of the mother or father to the respondent.

ECR-R measure the level of adult romantic attachment with two dimensions. ECR-R subscale scores for the two attachment dimensions of anxiety and avoidance. They have 18 items each and are determined by calculating mean scores; lower scores on both dimensions reflect more secure attachment styles and higher scores on one or both suggest more insecure attachment styles [2].

Open-ended Questions

The open-ended questions were focused on whether perception of early parent attachment has effect on adult romantic attachment style. The intention was to compensate the drawback of structured questionnaire by letting respondents to express their personal opinion, attitude and experience freely in their own words.

\subsection{Methods of Data Analysis}

Prior to conducting the analyses, the data collected were examined for accuracy of data entry, normality, missing values and collinearity. The data were found to have dependable data, normal distribution, no significant missing values and the scales and subscales which were considered as independent variables were not collinear. Person correlation was run to examine the relationship adult attachment and relationship satisfaction. Multiple regressions were run with attachment anxiety and attachment avoidance as the independent variables and relationship as dependent variables.

\section{Results}

The majority $(71.9 \%)$ of the respondents were in the age category of 26 to 40 years old, which is relatively in early 
adulthood category of chronological age. The other 56 (18.5\%) fall in the age category of 41-60 years old which is congruent to the chronological age of middle adulthood. Therefore, most, $90.2 \%$ of the respondents were in early and middle adulthood chronological age. The majority, 245 $(81.1 \%)$ of the respondents reported that they are married, 30 $(9.8 \%)$ reported that they are single, $19(6.2 \%)$. Sixty five percent of the respondents reported that they were reared by both biological mother and father, while $21.6 \%$ of the respondent reported that they were reared by only their biological mother. Two percent the respondents reared by their biological fathers and $6.3 \%$ of the respondents were reared by others like uncles and aunts. Therefore, most participants involved in this study are reared by their biological parents (mother and father) together.

Table 1. Demographic Data (Categorical) $(n=306)$.

\begin{tabular}{lll}
\hline Demographic Variable & Frequency & Valid Percent \\
\hline Sex & & \\
Female & 157 & 51.3 \\
Male & 149 & 48.7 \\
Total & 306 & 100 \\
Age & & \\
20- 25 years old & 21 & 6.9 \\
26-40 years old & 218 & 71.9 \\
41-60 years old & 56 & 18.5 \\
$>60$ years old & 8 & 2.6 \\
Total & 303 & 100 \\
Marital status & & \\
Married & 245 & 81.1 \\
Cohabited & 19 & 6.3 \\
Divorced & 7 & 2.3 \\
Single & 30 & 9.9 \\
Total & 302 & 100 \\
Caregiver during childhood & & \\
Mother & 65 & 21.6 \\
Father & 8 & 2.7 \\
Both father and mother & 197 & 65.4 \\
Grandmother & 9 & 3.0 \\
Grandfather & 3 & 1.0 \\
Others (uncle, aunt, step father, step & 19 & 6.3 \\
mother) & 301 & 100 \\
Total & & \\
\hline
\end{tabular}

Table 2. Bivariate Correlation among Variables.

\begin{tabular}{lllll}
\hline Measures & $\mathbf{1}$ & $\mathbf{2}$ & $\mathbf{3}$ & $\mathbf{4}$ \\
\hline Aanx & 1 & & & \\
Aavo & $.55^{*}$ & 1 & & \\
CM & $-.21^{*}$ & $-.13^{*}$ & 1 & 1 \\
CF & -.11 & -.01 & $.65^{*}$ & 1 \\
\hline
\end{tabular}

Note: $A a n x=$ Attachment anxiety, Aavo=Attachment avoidance, $\mathrm{CM}=$ closeness with mother, $\mathrm{CF}=$ closeness with father. association with closeness to mother $(\mathrm{r}=.21, \mathrm{p}<.001)$. Attachment avoidance had statistically significant negative association with closeness with mother $(\mathrm{r}=13, \mathrm{p}<0.01)$. However closeness with the father had no statistically significant relationship with neither attachment anxiety nor attachment avoidance.

To triangulate this quantitative relationship analysis of early attachment experience and adult romantic attachment style, an open-ended question was forwarded for the same informants. Exclusively almost all informants explained the impact of early attachment experience on adult attachment style. Sample selected description given by key informants are given below.

Informant 1: No questions about it. Child rearing practice has great impact on children life style especially on their friendly relationship. A child who grows in a family characterized by transparency, free discussion, tends to reflect these behaviors when he/she grown up in their own relationship. In the contrary, the one who grows in authoritative and ignorant family, will not give place for others, reflect no self confidence and no free discussion rather became self absorbent and remain silent until the problem became roofed. Moreover, to get acceptance from the partner, he/she might perform wrong and unacceptable acts. In his/her relationship no expressed love, no transparency, no trust and lives always in discomfort in his/her relationship (a 45 years old male informant).

Informant 2: In my opinion the attachment that children have had with their parents has great contribution in their adulthood life. For instance my mother devoted herself while she was nurturing me. I was growing without a father. Now I have children. I am reflecting my strong personality to rear my children like my mother did for me. Moreover, I am not only striving to be good mother but also good wife because I do not want my children to grow without a father and I want to be a model for them, (a 36 year old female informant).

These explanations given by informants imply how much early attachment experience influence later interpersonal functioning. Therefore, the qualitative result obtained from informants is much stronger than the quantitative analysis (correlation) but still within the same realm. Lower score in the perception of early attachment experience (low score in closeness with mother and low score in closeness with father) relate in insecure attachment during adulthood and higher score in perception of early attachment experience (closeness with mother and closeness with father) related to secure attachment during adulthood romantic relationship.

Attachment anxiety had statistically significant negative

Table 3. Regressions with Closeness with Parents on Adult Attachment.

\begin{tabular}{lllll}
\hline & Beta & t & p & F \\
\hline Regression 1 & & & & \\
DV: Anxiety & & & & \\
IV: Closeness with Father & -.059 & -.719 & .473 & .200 \\
Closeness with Mother & -.105. & -1.284 & .023 \\
Regression 2 & & & \\
\hline
\end{tabular}




\begin{tabular}{llllll}
\hline & Beta & t & p & F & R-Square \\
\hline DV: Avoidance & & & & & \\
IV: Closeness with Father & .081 & .979 & .328 & 1.492 & .012 \\
Closeness with Mother & -.142 & -1.717 & .087 & \\
\hline
\end{tabular}

Note: $* \mathrm{P}<0.01$

Regression analysis of both closeness with mother and closeness with father did not predict significantly adult attachment styles. This implies the level of closeness with parents and parental figures has no more statistically significant impact on the adult attachment style with their romantic partners.

\section{Discussion}

It was hypothesized that early attachment experience predicts adult romantic attachment style. Higher score in closeness with mother and higher score in closeness with father will result in lower score in attachment anxiety and lower score in attachment avoidance (secure attachment). Lower score in closeness with mother and lower score in closeness with father will result in higher level attachment anxiety and higher level of attachment avoidance.

The direction of correlations is consistent with those reported in the literature $[6,10,16]$. Individuals who get trust, communication and less alienation (higher score on closeness with father and closeness with mother) are more likely to approach later interpersonal relationship in a positive way, secure attachment style. Although the degree of impact depends on attachment figures, based on attachment theory, both mother and father figures should have an impact on children's formation of attachment style. Unlike what was predicted, early attachment experiences with parental figures were not strong predictor of current attachment style. Therefore, neither closeness with the father nor closeness with the mother predicts adult romantic attachment style. This result is analogous to some of the previous research results studies [16] and is contrary to other previous research reports $[6,10]$.

One possible explanation for the non-confirmation of this hypothesis could be, even though early child parent attachment is essential in the construction of an adult romantic attachment related behaviors and feelings in close relationships, any given intimate relationship experience with a specific romantic relationship provides an opportunity to reconstruct or work through the attachment memory established during infancy and childhood. Change toward attachment security is always possible if an adult has the opportunities to repeatedly engage in model disconfirming relationship experience and partners. Moreover, the scarcity of empirical evidences done on this area created a challenge to the present researcher to compare and contrast the findings.

The unexpected weak associations and prediction between early attachment experience and adult romantic attachment style could be attributed to different reasons. Some of them perhaps might be related to lack of recalling their past memory of the respondents, social desirability or unsuitability of the measure used to collect perception of early attachment experience.

\section{Conclusions and Implications}

The result had very weak association and prediction power between perception of early parental attachment experience and adult attachment style.. Hence, early attachment experience did not significantly predict adult attachment and other functional relationships during adulthood in the present study.

The present finding suggests that although the construction of adult's romantic attachment style is partly based on early parent-child attachment, there is an opportunity to reconstruct or work through the attachment memory established beyond infancy or childhood. The present research result shows that early parent-child attachment had very little impact in couple's romantic attachment. Actually, this result is relatively inconsistent with most of the previous conceptions of the relationship between early attachment experience and adult romantic attachment style. The findings from the qualitative analysis however, supported the previous conceptualization. The quantitative analysis also supported the hypothesized relationship but fails to predict significantly. Therefore, researchers who want to extend or replicate this issue shall focus on the instrument (IPPA) used to collect data from adults about the perception of early attachment experience.

\section{Limitation of the Study}

There are two major limitations of the present study. First, the present researcher more relay on self-report measures and open-ended questions. However, it may result in some inaccuracy in report of attachment style due to social desirability effect. Because insecure attachment involves defensiveness, participants with insecure attachment styles may under-report their sense of insecurity. Moreover, it would be necessary to assess the importance of attachment style relative to other factors like social desirability that may influence attraction and partner's choices. Another potential problem could be in the retrospective attachment measure used in the perception of early attachment experience. Individuals retrospective account of early attachment experience may have more to do with their current state of mind or a function of reconstructed and reinterpreted memory of early parent child attachment than the actual reflection of the early attachment experience in their childhood. Therefore, the degree to which the retrospective attachment assessment is meaningfully related to the early 
parent attachment needs to be addressed specifically in the future studies.

\section{References}

[1] Ainsworth, M. D. S., Blehar, M. C., Waters, E., and Wall, S. (1978). Patterns of attachment: A psychological study of the strange situation. Hillsdale, NJ: Lawrence Erlbaum Associates.

[2] Armsden, G. C. and Greenberg, M. T. (1987). The Inventory of Parent and Peer Attachment: Individual differences and their relationship to psychological wellbeing in adolescence. Journal of Youth and Adolescence, 16.427-454.

[3] Bowlby, J. (1988). A secure base. New York: Basic Books.

[4] Bowlby, J. (1973). Attachment and loss: Separation, anxiety and anger. New York: Basic Books.

[5] Bowlby, J. (1969). Attachment. New York: Basic Books.

[6] Cassidy, J. (2001). Truth, lies and intimacy: An attachment perspective. Attachment and Human Development, 3, 121155 .

[7] Collins, N. L. and Read, S. J. (1994). Cognitive representation of attachment to attachment: The structure and function of working models. Advances in personal relationships: Attachment process in adulthood, 5, 53-90.

[8] Collins, N. L. and Read, S. J. (1990). Adult attachment, working models, and relationship quality in dating couples. Journal of Personality and Social Psychology, 58, 644-663.
[9] CSA. (2007). Summary Report of the census of Ethiopia, Addis Ababa.

[10] Feeney, J. A. (2008). Adult romantic attachment: Developments in the study of couple relationships. In J. Cassidy and P. R. Shaver (Eds.). The handbook of attachment: Theory, research, and clinical applications (2nd ed., pp. 456481). New York: Guilford Press.

[11] Fraley, R. C., Waller, N. G. and Brennan, K. A. (2000). An item response theory analysis of self-report measures of adult attachment. Journal of Personality and Social Psychology, 78, 350-365.

[12] Hazan, C. and Shaver, P. R. (1987). Romantic love conceptualized as an attachment process. Journal of Personality and Social Psychology, 52, 511-524.

[13] ISDP (2004). Patterns and universals of adult romantic attachment across 62 cultural regions. Journal of CrossCultural Psychology, 35, 367-401.

[14] Loubser, J. (2007). Attachment theory and adult intimate relationships. Master thesis, Stellenbosch University.

[15] Shi, L. (2003). The Association between adult attachment styles and conflict resolution in romantic relationships. American Journal of Family Therapy, 31, 143-157.

[16] Shieh, M. (2000). The influence of perception of the early attachment experience on adult.

[17] Simpson, A. and Rholes, W. (2012). Adult Attachment Orientations, Stress, and Romantic Relationships. Advances in Experimental Social Psychology, Vol. 45, 279-328. 